\title{
Seismic Retrofitting Methods Newly Developed for Railway Concrete Structures
}

\author{
Tadayoshi Ishibashi ${ }^{1}$, Takeshi Tsuyoshi ${ }^{1}$ and Kaoru Kobayashi ${ }^{2}$
}

Received 25 June 2003, accepted 20 December 2003

\begin{abstract}
Since the Hyogo-Ken Nanbu Earthquake in 1995, seismic retrofitting of existing RC columns of railway structures has been carried out. This paper first describes conventional seismic retrofitting methods and introduces two new seismic retrofitting methods that can be easily applied in narrow spaces. An outline of experimental results for these new seismic retrofitting methods is provided and the relevant design methods are described. In the first method, called the RB method, retrofitting bars are arranged so as to keep the value of $\gamma_{\mathrm{i}} \cdot V_{\mathrm{yd}} / V_{\mathrm{mu}}\left(\gamma_{\mathrm{i}}\right.$ : safety factor, $V_{\mathrm{yd}}$ : shear strength, $V_{\text {mu}}$ : shear at flexural strength) above 1.5. In the second method, called the single-face method, retrofitting bars and retrofitting plates are arranged so as to keep the values of $\gamma_{\mathrm{i}} V_{\mathrm{yd}} / V_{\mathrm{mu}}$ and $\gamma_{\mathrm{i}} V_{\mathrm{yd}} / V_{\mathrm{mu}}$ above 2.0 and 1.4, respectively.
\end{abstract}

\section{Introduction}

After the Hanshin-Awaji Earthquake Disaster on 17 January 1995, the authorities at the Ministry of Transportation issued a notification on seismic retrofitting to railway companies. Following the recommendations of this notification, the columns of reinforced concrete rigid-frame structures having shear capacity smaller than the shear at flexural capacity were subject to seismic retrofitting. In areas served by the East Japan Railway Company, over ten thousand columns have been retrofitted on the Shinkansen Lines and conventional lines in the South-Kanto and Sendai areas to date. However, spaces under railway viaducts are often used for stores and offices, especially in urban areas. Therefore, development of new seismic retrofitting methods applicable to these areas is one of the important issues for the improvement of railway lines' seismic safety.

Citing examples of conventional seismic retrofitting techniques, this paper reports on new retrofitting methods that can be applied to the spaces under railway viaducts used for stores and offices.

\section{Examples of conventional seismic retrofitting methods used for actual railway concrete structures}

Figure 1 shows the seismic retrofitting design procedure for railway structures. For seismic retrofitting of railway rigid frame concrete railway structures, shear retrofitting and ductility retrofitting of columns are the main focus. Use of the steel jacket method has been

\footnotetext{
${ }^{1}$ Structural Eng. Center, Construction Dept., East Japan Railway Company, Japan E-mail: ishibashi@jreast.co.jp

${ }^{2}$ Frontier Service Development Laboratory, East Japan Railway Company, Japan
}

common for these types of seismic retrofitting because this method is advantageous in terms of cost and execution workability. Figure 2 shows mechanical joints de-

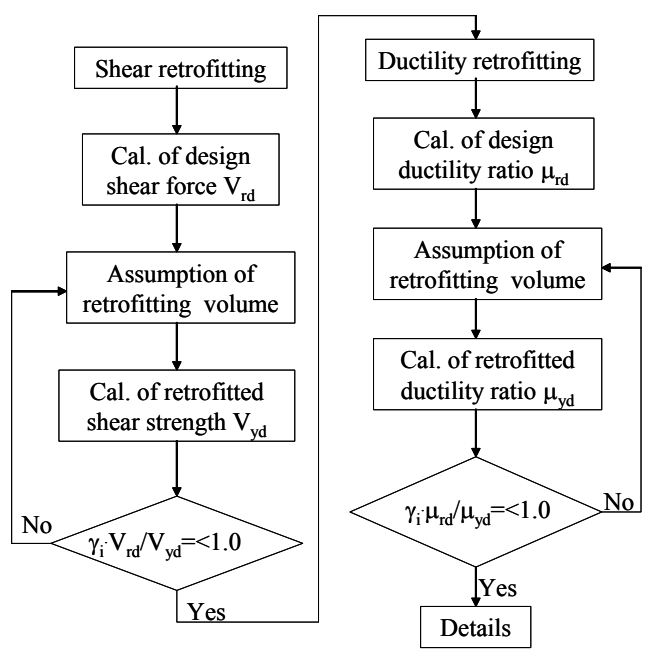

Fig.1 Seismic retrofitting design procedure.

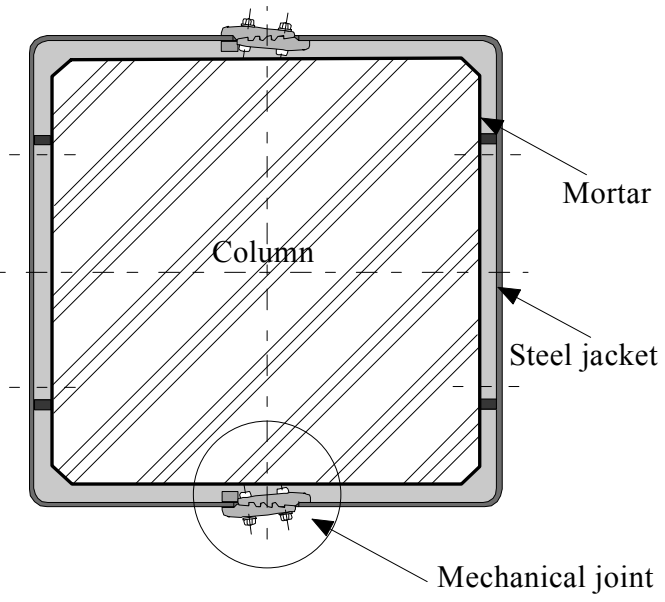

Fig. 2 New mechanical joint for steel jacket method. 


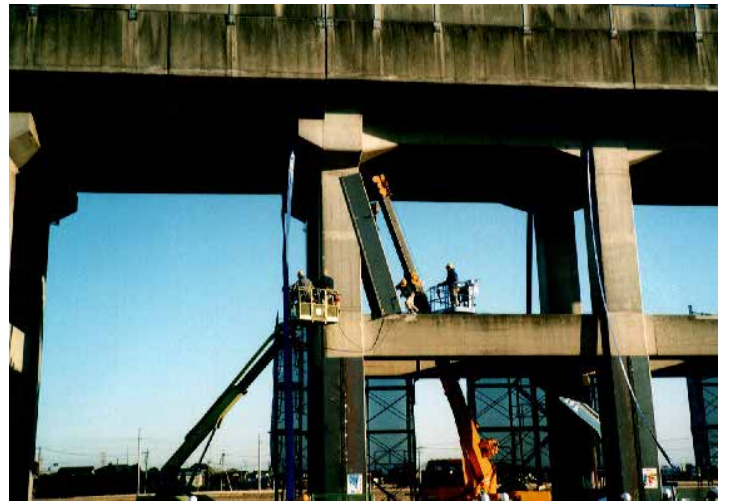

Fig. 3 Execution of steel jacket method.

veloped by the authors for the steel jacket method. These mechanical joints eliminate the need for melting works on site, thereby improving executability (Fig. 3). Other jacket methods used for railway structures are the RC jacket method, the carbon sheet jacket method, and the aramid sheet jacket method are applied. These methods are selected according to execution conditions and costs.

\section{Development of new retrofitting methods}

As mentioned above, the steel jacket method is mainly used for retrofitting of railway structures. However, the space under railway viaducts is often used for stores and offices, especially in urban areas. This makes it very difficult for large construction machinery like cranes used for the steel jacket method, to gain access to sites. In such cases, the steel jacket method requires a large amount of extra work to remove obstacles as well as payments to stores or offices, and seismic retrofitting is rarely carried out under such circumstances.

New seismic retrofitting methods have been developed to overcome this limitation. In the first method, which is called the RB method, external lateral reinforcements are arranged around an existing RC column and anchored at the four corners with L-shaped steels. The materials used for this method are steel bars, L-shaped steel anchorages, and mortar for anchorages, all of which are small items. As a result, this method can be executed purely by hand and is easily applied to existing RC columns in confined spaces. The second method, which is called the single-face method, uses a steel plate and reinforcing bars and allows execution of retrofitting work from only one face of the RC column section. The steel plate and reinforcing bars can be installed by hand. Therefore, with this method, seismic retrofitting executions can be carried out more easily than with the steel jacket method if the executed site is very narrow or spaces under superstructures are used for stores and offices.

Next, experimental results to confirm the performances of these two new seismic retrofitting methods are reported.

\section{RB method}

Figure 4 shows the outline of the RB method. The characteristics of this method have already been mentioned above. Reverse cyclic loading tests of RC columns retrofitted using the method proposed by the authors were carried out. The effects of seismic retrofitting were examined through experimental results for half-size specimens simulating columns on existing railway structures.

\subsection{Outline of investigation}

Table 1 lists the properties of all the specimens and the strengths of the materials used. Figure 5 shows the vertical and horizontal sections of all specimens. Figure 6 shows the anchorages for the external lateral reinforcement in detail. These anchorages consist of L-shaped steel and mortar. Threaded reinforcing bars anchored with lock nuts are used. Lock nuts are tightened with a hand wrench.

Table 2 shows the calculated characteristic values for the specimens. The notation $\mathrm{P}_{\mathrm{ycal}}$ is the calculated horizontal force when the axial reinforcements at the bottom of the columns, which are nearest to the compressive end, experience yielding. The notation $\mathrm{P}_{\text {ucal }}$ is the calculated horizontal force when the sectional force at the bottom of the column reaches the ultimate flexural strength. $V_{\text {yd }}$ is the calculated value of ultimate shear strength of the section, and $V_{\mathrm{mu}}$ is equal to $\mathrm{P}_{\text {ucal }}$. The ultimate strength is calculated based on actual material strength. In calculating the shear strength, the shear force held by external lateral reinforcement is estimated with the truss theory.

Standard specimen I has no lateral reinforcements. Specimens II to VII are retrofitted specimens. All retrofitted specimens contain no ordinary hoop reinforcements inside the section. The ratio of shear capacity to flexural capacity $\left(V_{\mathrm{yd}} / V_{\mathrm{mu}}\right)$ of specimen II is 2.35 . In this specimen, the external reinforcements are in contact with the surface of the column and the reinforcing bars are covered with post-cast mortar.

In specimen series III, the use of post-cast mortar is limited to anchorages, and the lateral reinforcements are exposed. Furthermore, the lateral reinforcements are in contact with the surface of the column.
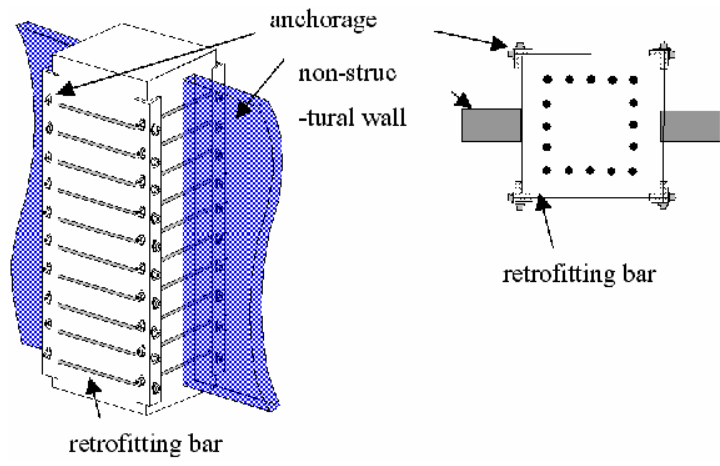

Fig.4 Schematic drawing of RB method. 
Table 1 Properties of all the specimens and strength of materials used.

\begin{tabular}{|c|c|c|c|c|c|c|c|c|c|c|c|c|c|c|c|c|c|}
\hline \multirow{3}{*}{$\begin{array}{c}\text { Specimen } \\
\text { number }\end{array}$} & \multirow[b]{2}{*}{ Section } & \multirow[b]{2}{*}{$\begin{array}{c}\text { Effec- } \\
\text { tive } \\
\text { depth }\end{array}$} & \multirow[b]{2}{*}{$\begin{array}{c}\text { Shear } \\
\text { span } \\
\text { la }\end{array}$} & \multirow[b]{3}{*}{$\mathrm{a} / \mathrm{d}$} & \multirow[b]{2}{*}{$\begin{array}{c}\text { Axial } \\
\text { reinforce- } \\
\text { ment } \\
\text { arrange- } \\
\text { ment }\end{array}$} & \multirow[b]{2}{*}{$\begin{array}{c}\text { Ratio of } \\
\text { axial } \\
\text { reinforce- } \\
\text { ment } \\
\mathrm{A}_{\mathrm{s}} /(\mathrm{b} \cdot \mathrm{d})\end{array}$} & \multirow[b]{2}{*}{\begin{tabular}{|c|} 
Lateral \\
external \\
reinforce- \\
ment \\
arrange- \\
ment \\
\end{tabular}} & \multirow[b]{2}{*}{\begin{tabular}{|c|} 
Ratio of \\
lateral \\
external \\
reinforce- \\
ment \\
$\mathrm{A}_{\mathrm{w}} /(\mathrm{b} \cdot \mathrm{s})$ \\
\end{tabular}} & \multirow[b]{2}{*}{$\begin{array}{c}\text { Axial } \\
\text { compre- } \\
\text { ssive } \\
\text { stress }\end{array}$} & \multicolumn{5}{|c|}{ Material strength } & \multicolumn{3}{|c|}{ Details of anchorage } \\
\hline & & & & & & & & & & $\begin{array}{c}\begin{array}{c}\text { Column } \\
\text { con- } \\
\text { crete }\end{array} \\
\end{array}$ & $\begin{array}{c}\text { Footing } \\
\text { con- } \\
\text { crete }\end{array} \mid$ & $\begin{array}{c}\text { Ancho- } \\
\text { rage } \\
\text { mortar }\end{array}$ & \begin{tabular}{|c|} 
Yield \\
strength \\
of axial \\
reinfor- \\
cement \\
\end{tabular} & \begin{tabular}{|c|} 
Yield \\
strength \\
of lateral \\
reinfor- \\
cements \\
\end{tabular} & \multirow{2}{*}{$\begin{array}{l}\text { Ancho- } \\
\text { rage } \\
\text { shape }\end{array}$} & \multirow{2}{*}{\begin{tabular}{|c|} 
L1 \\
$(\mathrm{mm})$
\end{tabular}} & \multirow{2}{*}{\begin{tabular}{|c|}
$\mathrm{L} 2$ \\
$(\mathrm{~mm})$
\end{tabular}} \\
\hline & $(\mathrm{mm} \times \mathrm{mm})$ & $(\mathrm{mm})$ & $(\mathrm{mm})$ & & (number) & $(\%)$ & $(\mathrm{mm})$ & $(\%)$ & $\left(\mathrm{N} / \mathrm{mm}^{2}\right)$ & \multicolumn{5}{|c|}{$\left(\mathrm{N} / \mathrm{mm}^{2}\right)$} & & & \\
\hline $\bar{I}$ & $400 \times 400$ & 360 & 1150 & 3.19 & $\begin{array}{l}\mathrm{D} 19 \times 16 \\
\end{array}$ & 3.18 & - & $\overline{-}$ & 0.98 & 23.2 & 23.2 & - & 370.5 & - & - & - & \\
\hline II & $400 \times 400$ & 360 & \begin{tabular}{|l|}
1150 \\
\end{tabular} & 3.19 & D19×16 & 3.18 & D13@65 & 0.98 & 0.98 & 26.6 & 26.5 & 45.3 & 377.2 & 354.6 & \begin{tabular}{|l|} 
TypeA \\
\end{tabular} & 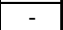 & 25 \\
\hline III-1 & $400 \times 400$ & 360 & 1150 & 3.19 & D19×16 & 3.18 & D13@65 & 0.98 & 0.98 & 20.1 & 20.7 & 47.6 & 377.2 & 354.6 & \begin{tabular}{|l|} 
TypeA \\
\end{tabular} & 40 & 25 \\
\hline III-2 & $400 \times 400$ & 360 & \begin{tabular}{|l|}
1150 \\
\end{tabular} & 3.19 & $\begin{array}{l}\mathrm{D} 19 \times 16 \\
\end{array}$ & 3.18 & D13@150 & 0.42 & 0.98 & 35.7 & 35.7 & 61.9 & 382.8 & 371.7 & TypeA & 40 & 25 \\
\hline III-3 & $400 \times 400$ & 360 & \begin{tabular}{|l|}
1150 \\
\end{tabular} & 3.19 & $\begin{array}{l}\mathrm{D} 19 \times 20 \\
\end{array}$ & 3.98 & D13@200 & 0.32 & 0.98 & 32.5 & 32.5 & 25.8 & 382.8 & 371.7 & \begin{tabular}{|l|} 
TypeC \\
\end{tabular} & 40 & - \\
\hline IV-1 & $400 \times 400$ & 360 & \begin{tabular}{|l|}
1150 \\
\end{tabular} & 3.19 & $\mathrm{D} 19 \times 16$ & 3.18 & D13@150 & 0.42 & 0.98 & 32.5 & 32.5 & 55.5 & 382.8 & 371.7 & TypeB & 40 & - \\
\hline IV-2 & $400 \times 400$ & 360 & 1150 & 3.19 & $\begin{array}{l}\text { D19×20 } \\
\end{array}$ & 3.98 & D13@200 & 0.32 & 0.98 & 31.8 & 31.8 & 45.3 & 382.8 & 371.7 & TypeB & 40 & - \\
\hline $\mathrm{V}-1$ & $400 \times 400$ & 360 & \begin{tabular}{|l|}
1150 \\
\end{tabular} & 3.19 & $\mathrm{D} 19 \times 16$ & 3.18 & D13@65 & 0.98 & 0.98 & 32.9 & 32.9 & 50.0 & 382.8 & 371.7 & \begin{tabular}{|l|} 
TypeA \\
\end{tabular} & 40 & 25 \\
\hline $\mathrm{V}-2$ & $400 \times 400$ & 360 & \begin{tabular}{|l|}
1150 \\
\end{tabular} & 3.19 & $\begin{array}{l}\mathrm{D} 19 \times 16 \\
\end{array}$ & 3.18 & D13@150 & 0.42 & 0.98 & 33.6 & 33.6 & 46.9 & 378.5 & 395.7 & TypeB & 40 & - \\
\hline V-3 & $400 \times 400$ & 360 & \begin{tabular}{|l|}
1150 \\
\end{tabular} & 3.19 & D19×16 & 3.18 & D13@150 & 0.42 & 0.98 & 43.2 & 43.2 & 40.5 & 378.5 & 395.7 & \begin{tabular}{|l|} 
TypeD \\
\end{tabular} & 40 & - \\
\hline V-4 & $400 \times 400$ & 360 & \begin{tabular}{|l|}
1150 \\
\end{tabular} & 3.19 & $\mathrm{D} 19 \times 16$ & 3.18 & D13@150 & 0.42 & 0.98 & 39.4 & 39.4 & 40.5 & 378.5 & 395.7 & \begin{tabular}{|l|} 
TypeD \\
\end{tabular} & 40 & - \\
\hline VI-1 & $600 \times 600$ & 550 & \begin{tabular}{|l|}
1650 \\
\end{tabular} & 3.00 & $\mathrm{D} 25 \times 24$ & 3.69 & D22@200 & 0.65 & 0.98 & 27.6 & 27.6 & 51.3 & 368.0 & 368.2 & TypeC & 60 & - \\
\hline VI-2 & $600 \times 600$ & 550 & \begin{tabular}{|l|}
1650 \\
\end{tabular} & 3.00 & $\mathrm{D} 25 \times 24$ & 3.69 & D29@200 & 1.07 & 0.98 & 33.0 & 33.0 & 53.9 & 368.0 & 391.9 & TypeC & 60 & - \\
\hline VII-1 & $400 \times 400$ & 360 & \begin{tabular}{|l|}
1150 \\
\end{tabular} & 3.19 & $\begin{array}{l}\mathrm{D} 19 \times 16 \\
\end{array}$ & 3.18 & D13@125 & 0.51 & 5.89 & 36.5 & 32.5 & 60.3 & 368.7 & 356.2 & TypeB & 40 & - \\
\hline VII-2 & $300 \times 300$ & 260 & 950 & 3.65 & D16×16 & 4.07 & D13@150 & 0.56 & 9.81 & 35.3 & 35.9 & 62.6 & 358.1 & 356.2 & TypeB & 40 & - \\
\hline
\end{tabular}

Table 2 Calculated values and testing values.

\begin{tabular}{|c|c|c|c|c|c|c|c|c|c|c|c|c|c|c|c|}
\hline \multirow{3}{*}{$\begin{array}{c}\text { Specimen } \\
\text { number }\end{array}$} & \multicolumn{10}{|c|}{ Calculated values } & \multicolumn{5}{|c|}{ Experimental values } \\
\hline & $\mathrm{P}_{\text {ycal }}$ & $\mathrm{P}_{\text {ucal }}$ & $\mathrm{V}_{\mathrm{c}}$ & $\mathrm{V}_{\mathrm{s}}$ & \multirow[b]{2}{*}{$\mathrm{V}_{\mathrm{c}} / \mathrm{V}_{\mathrm{mu}}$} & \multirow[b]{2}{*}{$\mathrm{V}_{\mathrm{s}} / \mathrm{V}_{\mathrm{mu}}$} & \multirow[b]{2}{*}{$\mathrm{V}_{\mathrm{yd}} / \mathrm{V}_{\mathrm{mu}}$} & \multirow{2}{*}{\begin{tabular}{|l|}
$\delta_{\mathrm{y} 1}$ \\
$(\mathrm{~mm})$ \\
\end{tabular}} & \multirow{2}{*}{$\begin{array}{l}\delta_{\mathrm{y} 0} \\
(\mathrm{~mm})\end{array}$} & \multirow{2}{*}{$\begin{array}{l}\delta_{\text {ycal }} \\
(\mathrm{mm})\end{array}$} & \multirow{2}{*}{\begin{tabular}{|l|}
$\mathrm{P}_{\text {ytest }}$ \\
$(\mathrm{kN})$ \\
\end{tabular}} & \multirow{2}{*}{\begin{tabular}{|l|}
$\mathrm{P}_{\text {utest }}$ \\
$(\mathrm{kN})$ \\
\end{tabular}} & \multirow{2}{*}{$\frac{\delta_{\text {yexp }}}{(\mathrm{mm})}$} & \multirow{2}{*}{$\frac{\delta_{\text {uexp }}}{(\mathrm{mm})}$} & \multirow{2}{*}{$\begin{array}{c}\text { Ductility } \\
\text { ratio } \mu\end{array}$} \\
\hline & $(\mathrm{kN})$ & (kN) & $(\mathrm{kN})$ & $(\mathrm{kN})$ & & & & & & & & & & & \\
\hline I & 196.3 & 247.0 & 159.9 & 0.0 & 0.65 & 0.00 & 0.65 & - & - & - & - & 210.0 & - & - & - \\
\hline II & 201.7 & 255.1 & 166.8 & 432.7 & 0.65 & 1.70 & 2.35 & 1.94 & 3.96 & 5.90 & 234.3 & 305.9 & 5.2 & 97.4 & 17.7 \\
\hline $\begin{array}{lll}\text { III-1 } \\
\end{array}$ & 197.3 & 245.9 & 153.0 & 432.7 & 0.62 & 1.76 & \begin{tabular}{|l|}
2.38 \\
\end{tabular} & 2.41 & 4.17 & 6.58 & 220.6 & 288.4 & 5.2 & 87.6 & 13.3 \\
\hline III-2 & 209.3 & 268.2 & 183.4 & 196.5 & 0.68 & 0.73 & 1.42 & 1.54 & 3.79 & 5.33 & 225.4 & 305.1 & 5.1 & 85.5 & 16.0 \\
\hline III-3 & 249.3 & 317.2 & \begin{tabular}{|l|}
190.3 \\
\end{tabular} & 147.4 & 0.60 & \begin{tabular}{l|l|}
0.46 \\
\end{tabular} & 1.06 & 1.86 & 4.01 & 5.87 & 290.5 & 363.0 & 5.6 & 76.1 & 13.0 \\
\hline IV-1 & 207.7 & 265.4 & \begin{tabular}{|l|}
178.5 \\
\end{tabular} & 196.5 & 0.67 & \begin{tabular}{l|l|}
0.74 \\
\end{tabular} & \begin{tabular}{l|}
1.41 \\
\end{tabular} & 1.66 & 3.85 & 5.51 & 210.8 & 295.3 & 5.5 & 80.9 & 14.7 \\
\hline IV-2 & 248.8 & 316.4 & 147.4 & 147.4 & 0.47 & 0.47 & 0.93 & 1.89 & 4.03 & 5.92 & 286.7 & 344.3 & 6.7 & 77.8 & 13.1 \\
\hline V-1 & 208.0 & 265.8 & 178.5 & 453.5 & 0.67 & \begin{tabular}{l|l|}
1.71 \\
\end{tabular} & 2.38 & 1.65 & 3.85 & 5.50 & 236.4 & 310.0 & 5.3 & 102.4 & 18.6 \\
\hline $\mathrm{V}-2$ & 206.3 & 264.2 & 180.5 & 209.2 & 0.68 & \begin{tabular}{l|l|}
0.79 \\
\end{tabular} & 1.48 & 1.47 & 3.65 & 5.12 & 228.6 & 274.7 & 5.9 & 66.6 & 13.0 \\
\hline $\mathrm{V}-3$ & 210.5 & 270.3 & 196.2 & 209.2 & 0.73 & 0.77 & 1.50 & 1.19 & 3.48 & 4.67 & 226.4 & 298.2 & 5.0 & 80.2 & 17.2 \\
\hline $\mathrm{V}-4$ & 209.0 & 268.8 & 190.3 & 209.2 & 0.71 & 0.78 & 1.49 & 1.28 & 3.54 & 4.82 & 230.4 & 292.3 & 5.0 & 62.7 & 13.0 \\
\hline VI-1 & 541.9 & 690.6 & 370.8 & 681.7 & 0.54 & 0.99 & 1.52 & 2.40 & 4.49 & 6.89 & 570.9 & 777.9 & 7.9 & 102.9 & 14.9 \\
\hline VI-2 & 549.2 & 705.5 & 393.4 & 1204.7 & 0.56 & 1.71 & 2.27 & 2.07 & 4.37 & 6.44 & 541.3 & 769.1 & 8.0 & 101.4 & 15.7 \\
\hline VII-1 & 282.2 & 331.7 & 224.6 & 226.0 & 0.68 & \begin{tabular}{l|l}
0.68 \\
\end{tabular} & 1.36 & 1.90 & 3.96 & 5.86 & 334.7 & 392.4 & 4.9 & 62.9 & 10.8 \\
\hline VII-2 & 178.8 & 192.3 & \begin{tabular}{|l|}
151.1 \\
\end{tabular} & 136.0 & 0.79 & 0.71 & 1.49 & 2.11 & 4.22 & 6.33 & 223.3 & 248.2 & 4.6 & 49.3 & 7.8 \\
\hline
\end{tabular}
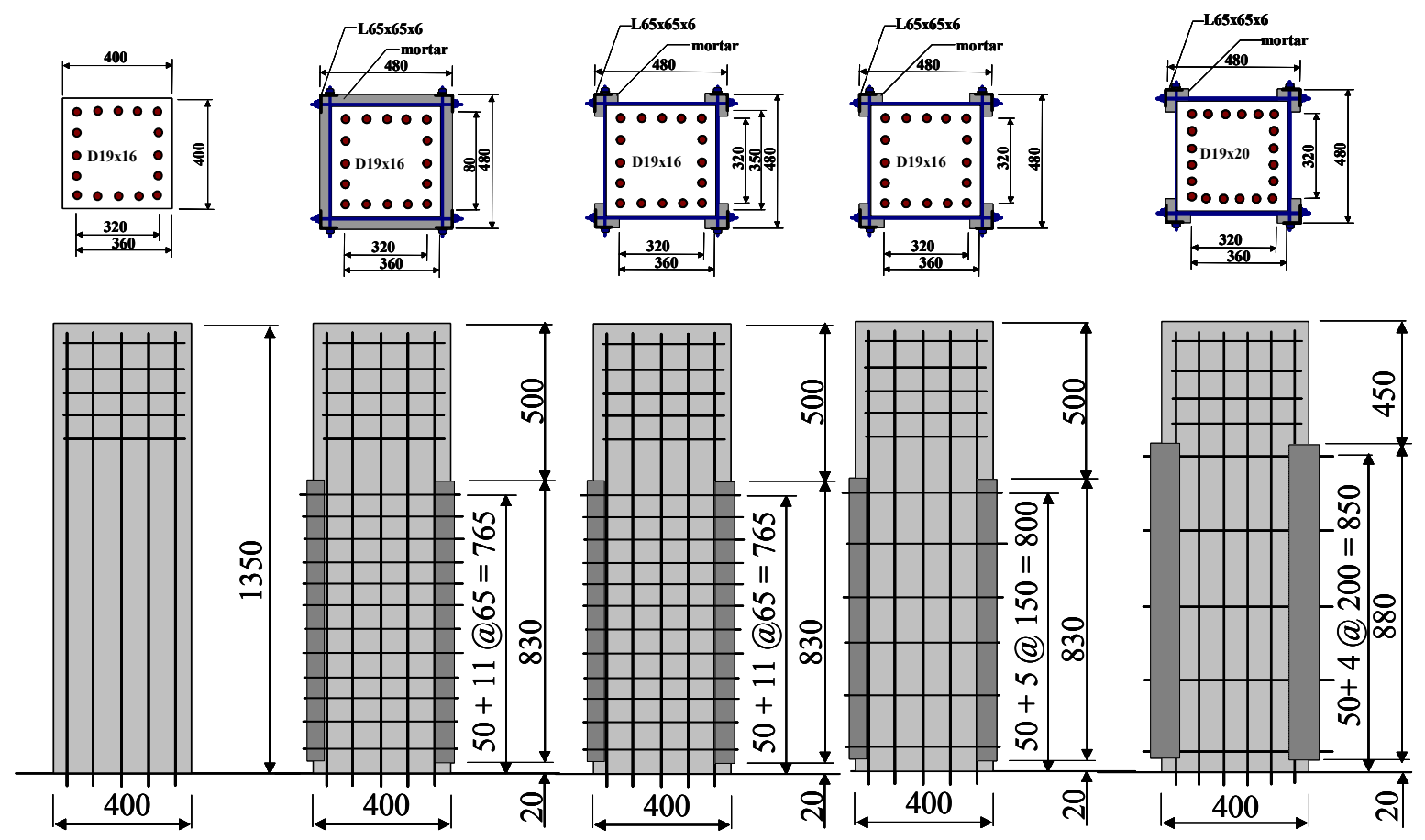

(a) I

(b) II

(c) III-1

(d) III-2

(e) III-3

Fig. 5 Vertical and horizontal sections. 

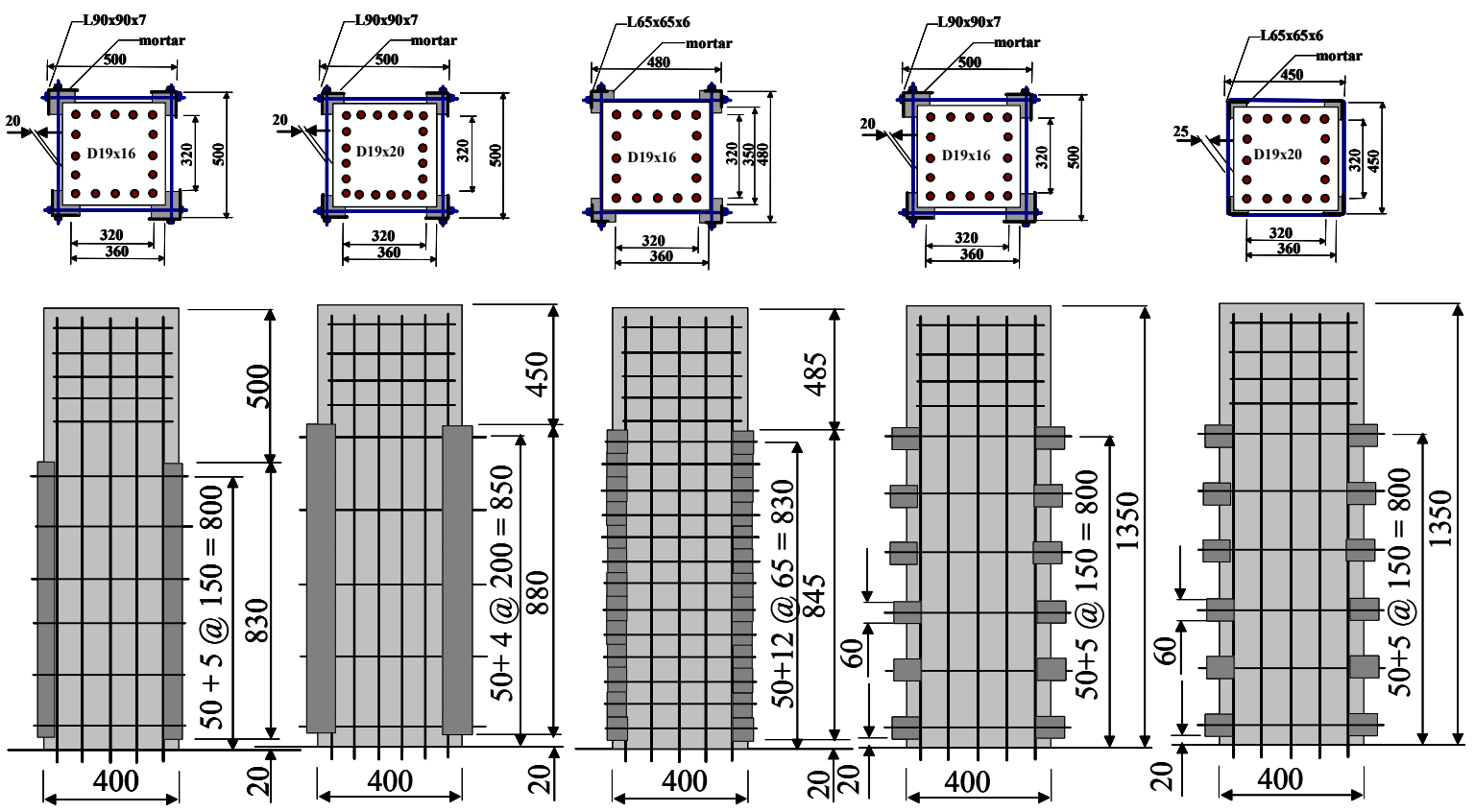

(f) IV-1

(g) IV-2

(h) $\mathrm{V}-1$

(i) V-2

(j) V-3
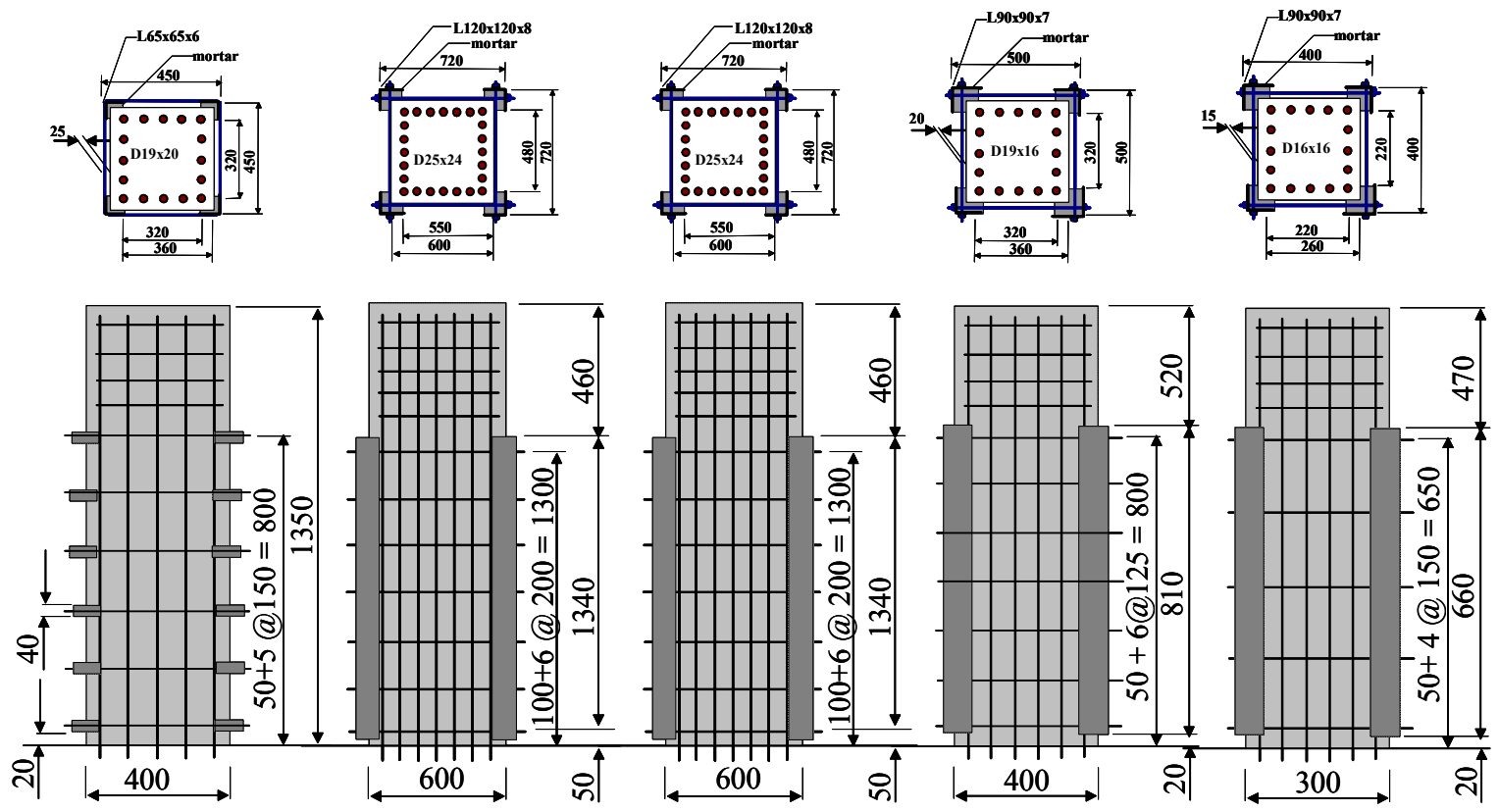

(k) V-4

(1) VI-1

(m) VI-2

(n) VII-1

(o) VII-2

Fig. 5 Vertical and horizontal sections.

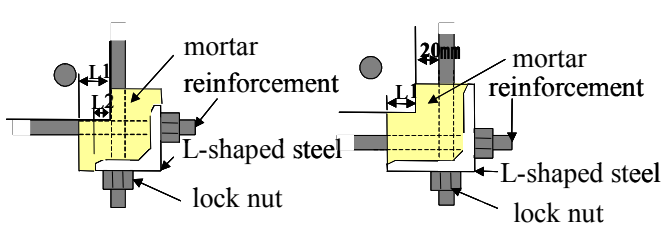

Type A

Type B

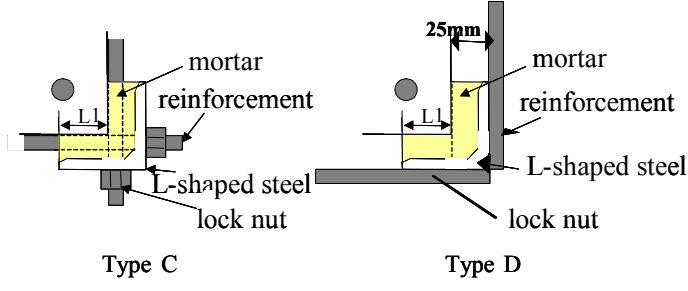

Fig. 6 Details of anchored partsl. 
Likewise in specimen series IV, the use of post-cast mortar is limited to anchorages, and the lateral reinforcements are exposed. The clearance between external lateral reinforcements and the surface of the column is $20 \mathrm{~mm}$. This clearance is provided because in actual retrofitting executions, lateral reinforcements cannot always be arranged flush against the surface of the column because the surface of the column is not always flat.

In specimen series $\mathrm{V}$, anchorages are separated at each rung of the external lateral reinforcement in the axial direction.

In specimen series VI, the size of the section is 600 $\mathrm{mm} \times 600 \mathrm{~mm}$.

Finally, in specimen series VII, the axial compressive

Table 3 Experimental parameters.

\begin{tabular}{|c|c|r|r|c|r|r|}
\hline $\begin{array}{c}\text { Specimen } \\
\text { number }\end{array}$ & $\begin{array}{c}\text { Additiona } \\
1 \text { cover } \\
\text { mortar }\end{array}$ & $\mathrm{V}_{\text {yd }} / \mathrm{V}_{\text {mu }}$ & $\begin{array}{c}\text { column surface lateral } \\
\text { reinforcement clearance } \\
(\mathrm{mm})\end{array}$ & $\begin{array}{c}\text { L-shaped } \\
\text { steel } \\
\text { clearance }\end{array}$ & $\begin{array}{c}\text { Section } \\
\text { size } \\
(\mathrm{mm})\end{array}$ & $\begin{array}{c}\text { Compre- } \\
\text { ssive axial } \\
\text { stress } \\
\left(\mathrm{N} / \mathrm{mm}^{2}\right)\end{array}$ \\
\hline I & - & 0.65 & 0 & - & $400 \times 400$ & 0.98 \\
\hline II & exist & 2.35 & 0 & no & $400 \times 400$ & 0.98 \\
\hline III-1 & no & 2.38 & 0 & no & $400 \times 400$ & 0.98 \\
\hline III-2 & no & 1.42 & 0 & no & $400 \times 400$ & 0.98 \\
\hline III-3 & no & 1.06 & 0 & no & $400 \times 400$ & 0.98 \\
\hline IV-1 & no & 1.41 & 20 & no & $400 \times 400$ & 0.98 \\
\hline IV-2 & no & 0.93 & 20 & no & $400 \times 400$ & 0.98 \\
\hline V-1 & no & 2.38 & 0 & yes & $400 \times 400$ & 0.98 \\
\hline V-2 & no & 1.48 & 20 & yes & $400 \times 400$ & 0.98 \\
\hline V-3 & no & 1.5 & 25 & yes & $400 \times 400$ & 0.98 \\
\hline V-4 & no & 1.49 & 25 & yes & $400 \times 400$ & 0.98 \\
\hline VI-1 & no & 1.52 & 0 & no & $600 \times 600$ & 0.98 \\
\hline VI-2 & no & 2.27 & 0 & no & $600 \times 600$ & 0.98 \\
\hline VII-1 & no & 1.36 & 20 & no & $400 \times 400$ & 5.89 \\
\hline VII-2 & no & 1.49 & 15 & no & $300 \times 300$ & 9.81 \\
\hline
\end{tabular}
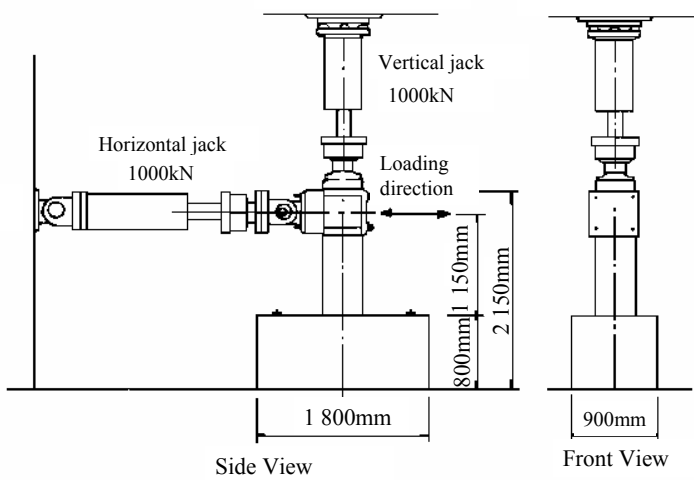

Shear span is $1,650 \mathrm{~mm}$ for VI-1,2 and $950 \mathrm{~mm}$ for VII- 2 .

Height of footing is $700 \mathrm{~mm}$ for VI-1,2 and $800 \mathrm{~mm}$ for VII-2

Fig. 7 Loading system.

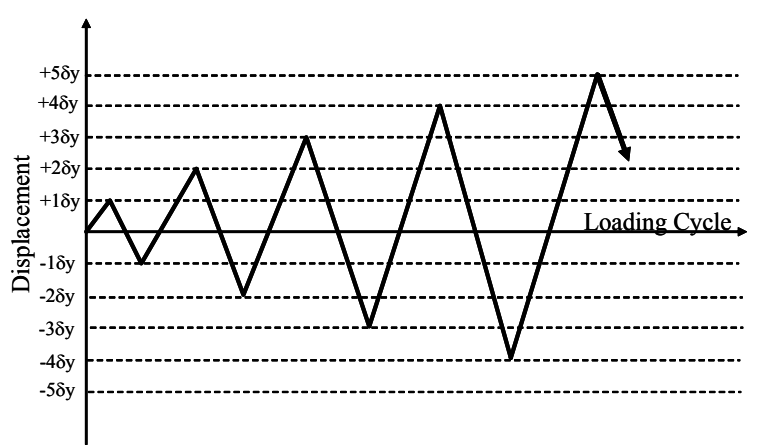

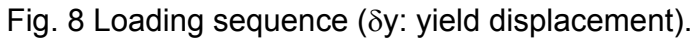

stress is set as $5.89 \mathrm{~N} / \mathrm{mm}^{2}$ and $9.81 \mathrm{~N} / \mathrm{mm}^{2}$.

Table 3 lists the experimental parameters described above. As shown in Fig. 5, a space is secured between the lower edge of the anchorages and the footings in order to ensure that the anchorages do not affect the ultimate flexural strength.

Figure 7 shows the loading systems. All specimens were tested under constant axial load, and reverse static cyclic displacement was applied. The standard yield deformation of each specimen $\left(\delta_{\text {ytest }}\right)$ is defined as the experimental deformation at which the reinforcements that have the largest effective depth experience yielding. Loading was carried out up to $\delta_{\text {ytest }}$ under load control with a loading step of 4.9 to $9.8 \mathrm{kN}$. Thereafter, cyclic displacement at an integer number equal to a multiple of $\delta_{\text {ytest }}$ was applied $\left(2 \delta_{\text {ytest }}, 3 \delta_{\text {ytest }}, 4 \delta_{\text {ytest }}, \ldots\right)$. At each loading displacement, one cycle was applied (Fig. 8). The period of each loading cycle was at least 120 seconds. The loading test was continued until the horizontal force fell to less than $50 \%$ of the ultimate horizontal strength.

\subsection{Experimental results and discussions}

\section{(1) Effects of new retrofitting method}

Figure 9 shows the envelopes of cyclic load-displacement relations of specimens I, II, and III-1. Specimen I has no lateral reinforcement. The section of specimen II is entirely covered with post-cast mortar. The section of III-1 is covered only at anchorages with post-cast mortar. The ratio of shear capacity to flexural capacity of II and III-1 is 2.5. As can be seen in Fig. 9, deformability increased as a result of these retrofitting methods. Post-cast mortar had little influence on the deformability of the columns. Figure $\mathbf{1 0}$ shows damage conditions after loading tests.

\section{(2) Ratio of shear capacity to flexural capacity}

Figure 11 shows the envelopes of cyclic load-displacement relations for III-1, III-2, and III-3. The ratio of shear capacity to flexural capacity is 2.38 in the case of III-1, 1.42 in the case of III-2, and 1.06 in the case of III-3. The $\mathrm{x}$-axis is a non-dimensional value, displacement divided by the yield displacement, and so is the y-axis, which is horizontal force divided by the yield force. Specimen III-2, whose shear-to-flexural

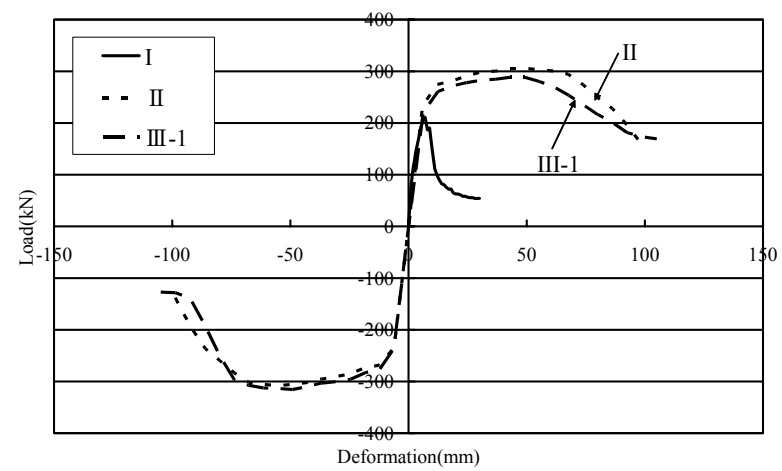

Fig.9 Envelope of cyclic load-displacement relations for specimens I, II, and III-1. 


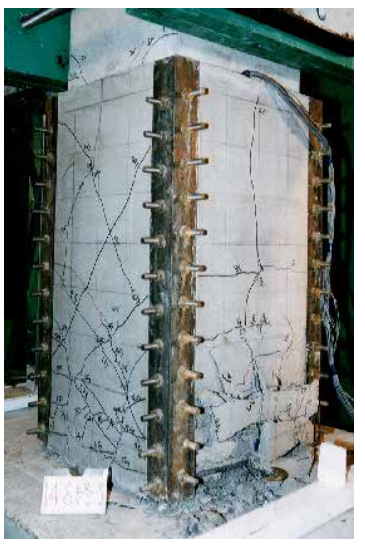

(a) II

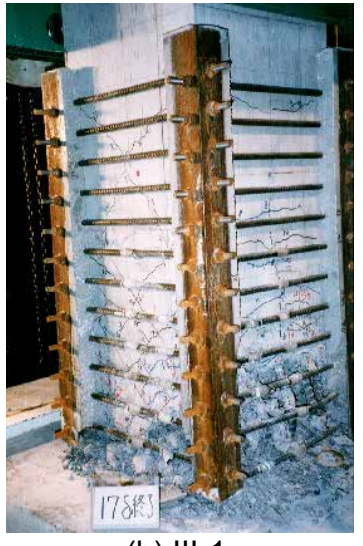

(b) III-1
Fig. 10 Post-test conditions.

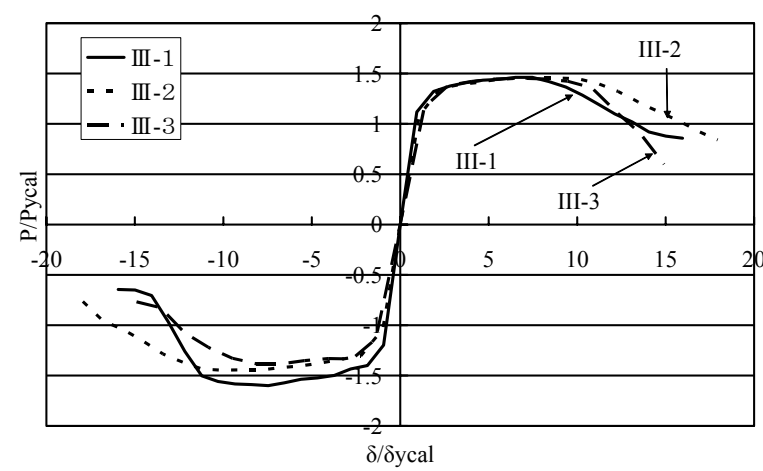

Fig. 11 Envelope of cyclic load-displacement relations for specimens III-1, III-2, and III-3.

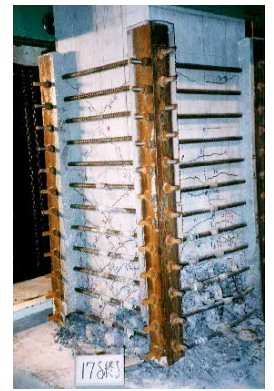

(a) III-1

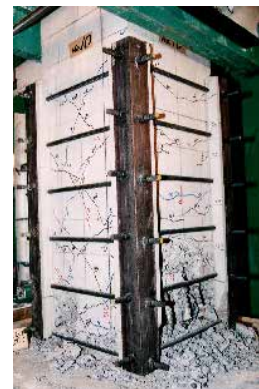

(b) III-2

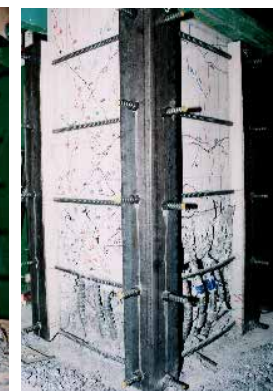

(c) III-3
Fig. 12 Specimens after tests.

capacity ratio is 1.42 , had the highest ductility. Specimens III-1 and III-3 had almost the same ductility. These experiments confirm that ductility is more or less constant where the shear-to-flexural capacity ratio exceeds 1.0. However, the failure mode of III-3 was shear. Figure 12 shows damage conditions after loading tests.

\section{(3) Separation between external lateral reinforce-} ment and surface of column

Figure 13 shows the envelopes of cyclic load-displacement relations for III-2 and IV-1, while Fig. 14 shows the same relations for III-3 and IV-2. In series III, the external lateral reinforcements were in contact with the column, whereas the series IV has clearance of

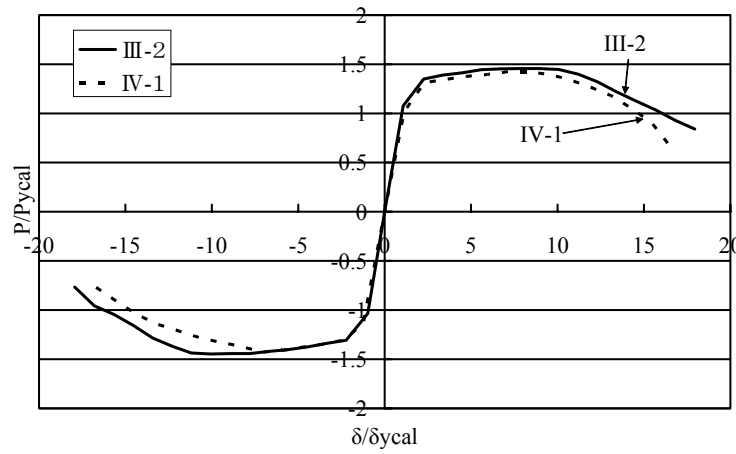

Fig. 13 Envelope of cyclic load-displacement relations for specimens III-2 and IV-1.

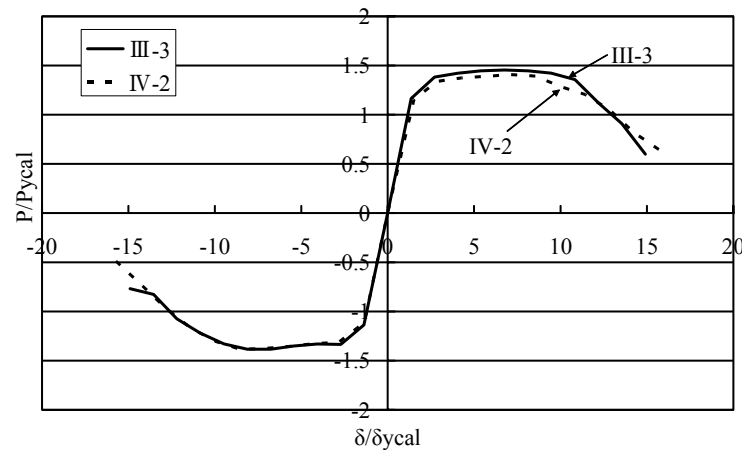

Fig. 14 Envelope of cyclic load-displacement relations for specimens III-2 and IV-2.

$20 \mathrm{~mm}$. Figure 13 shows that the ductility of specimen IV-1 with the $20 \mathrm{~mm}$ clearance is a little smaller than that of III-2. Figure 14 shows that III-3 and IV-2, whose shear-to-flexural capacity ratios are 1.0 , have almost the same ductility. Judging from these results, it can be stated that the clearance between external lateral reinforcement and the surface of the column has little effect on the ductility of retrofitted columns.

\section{(4) Separation of anchor parts}

Figure 15 shows the envelopes of cyclic load-displacement relations for specimens III-1 and V-1. The difference between these two specimens is the continuity of the anchorages in the column axial direction. Other parameters are almost the same. These specimens are fabricated in the same way.

As shown in Fig. 15, V-1 has higher ductility. This indicates that separating the anchorages has some influence on the ductility of the columns. Figure $\mathbf{1 6}$ shows the envelopes of cyclic load-displacement relations for specimens IV-1, V-2, V-3, and V-4. In these specimens, the main parameter is the size of the L-shaped steel at the anchorages, and the other parameters are almost constant. In the case of V-2 and V-4, the anchorages were crushed and the load decreased suddenly. On the other hand, in the case of V-3, the anchorages survived and higher ductility was attained. Therefore, through the use of this retrofitting method, 


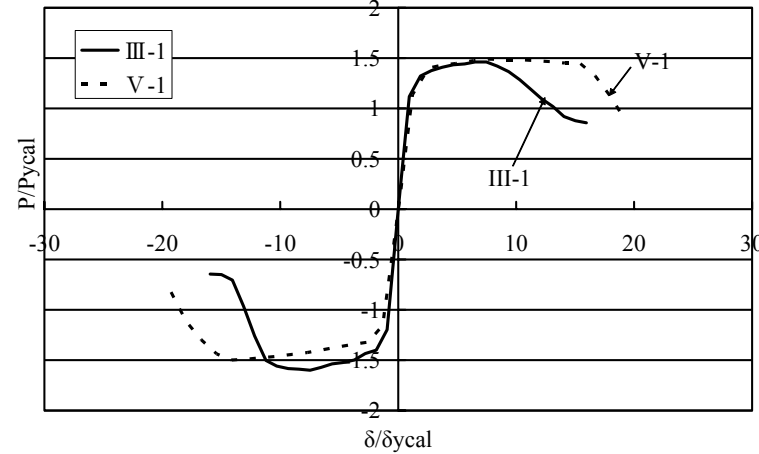

Fig. 15 Envelope of cyclic load-displacement relations for specimens III-1 and V-1.

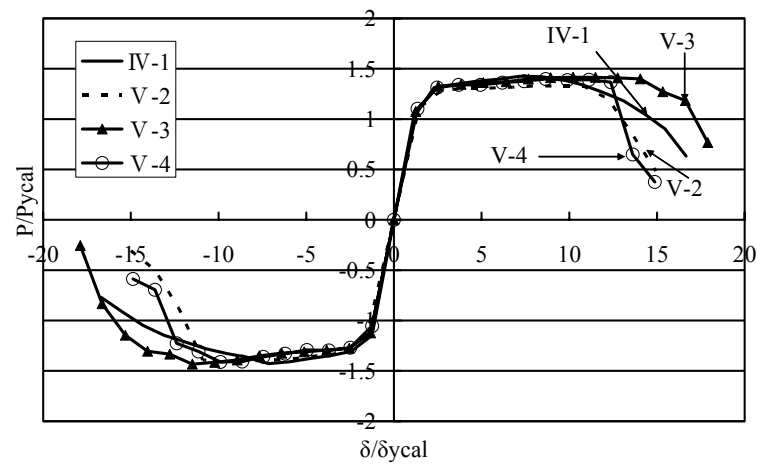

Fig. 16 Envelope of cyclic load-displacement relations for specimens IV-2, V-2, V-3 and V-4.

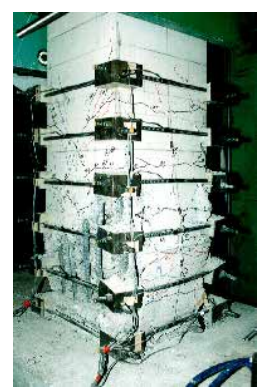

(a) $\mathrm{V}-2$

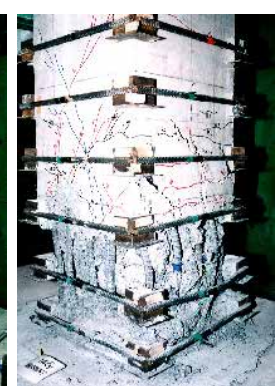

(b) V-3

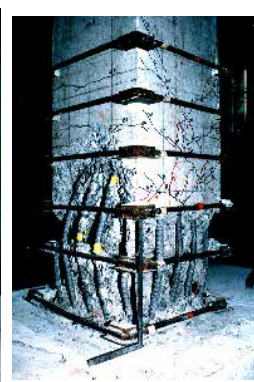

(c) V-4
Fig. 17 Specimens after tests.

adequate ductility is achieved as long as the anchorages remain undamaged. Figure 17 shows photos of V-2, V-3, and $\mathrm{V}-4$ after loading tests.

\section{(5) Section size}

Figure 18 shows the envelopes of cyclic load-displacement relations for specimen III-2 with a $400 \mathrm{~mm}$ square section and specimen VI-1 with a 600 $\mathrm{mm}$ square section. Other parameters without the ratio of shear capacity to flexural capacity are almost the same for these specimens. Both specimens exhibited almost the same ductility, as indicated in Fig. 18. As shown in Fig. 11, the ratio of shear capacity to flexural capacity did not have any influence on ductility capacity when the ratio was greater than 1.4 in the experiments here. Almost the same ductility was observed for

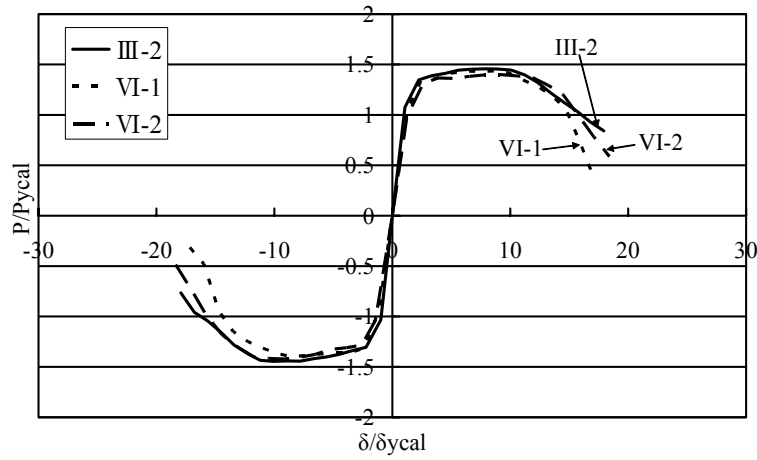

Fig. 18 Envelope of cyclic load-displacement relations for specimens III-2, VI-1 and VI-2.

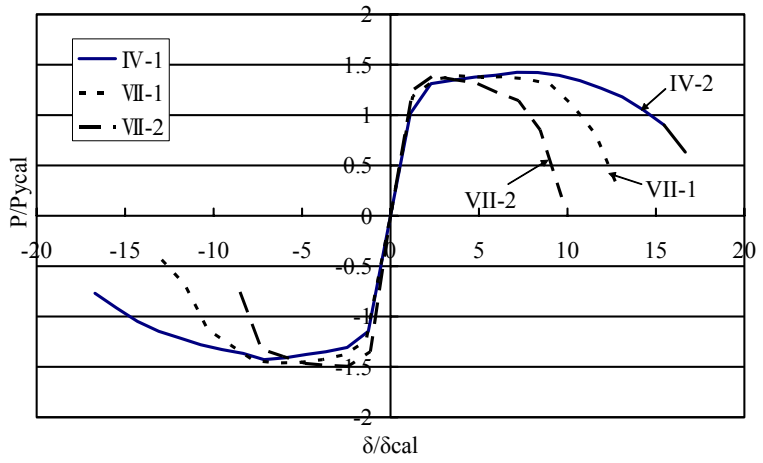

Fig. 19 Envelope of cyclic load-displacement relations for specimens IV-1, VII-1 and VII-2.

specimen VI-1, whose shear-to-flexural capacity ratio is 1.52, and specimen VI-2, whose shear-to-flexural capacity ratio is 2.27 . Ductility was not increased even where the shear-to-flexural capacity ratio exceeded 1.5. The same tendency was observed in the case of smaller specimens with a $400 \mathrm{~mm}$ square section.

\section{(6) Axial forces}

Figure 19 shows the envelopes of cyclic load-displacement relations for specimen IV-1 with an axial compressive stress of $0.98 \mathrm{~N} / \mathrm{mm}^{2}$, specimen VII-1 with an axial compressive stress of $5.89 \mathrm{~N} / \mathrm{mm}^{2}$, and specimen VII-2 with an axial compressive stress of 9.91 $\mathrm{N} / \mathrm{mm}^{2}$. In the case of larger axial compressive stress, ductility decreased with a sudden drop in load.

Table 2 lists experimental ductility ratio values. The ductility ratio is defined as the ratio of experimental ultimate displacement to calculated yield displacement (Fig. 20). Here, "experimental ultimate displacement" is defined as the displacement at which the load falls to the yield force. Figure 21 shows the relationships between the shear-to-flexural capacity ratio $\left(V_{\mathrm{yd}} / V_{\mathrm{mu}}\right)$ and the ductility ratio $(\mu)$ when the axial compressive stress is $0.98 \mathrm{~N} / \mathrm{mm}^{2}$. In this figure, specimens $\mathrm{V}-2$ and $\mathrm{V}-4$ are omitted because they failed as a result of damage in the anchorages. As shown in Fig. 21, the relationship between shear-to-flexural capacity ratio and ductility ratio indicates a weak, one-dimensional positive correlation 


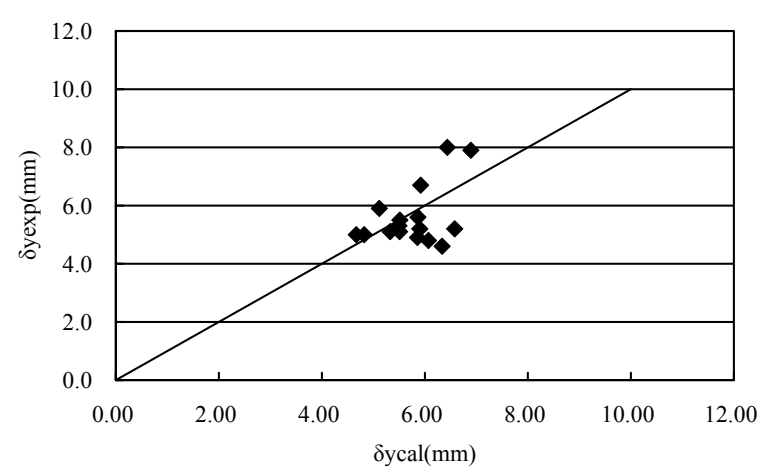

Fig. 20 Comparison between experimental values

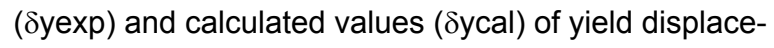
ments.

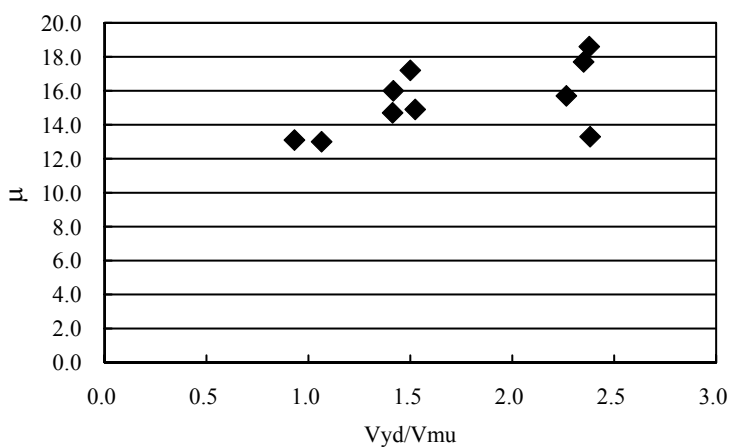

Fig.21 Relationship between Vyd/Vmu and ductility $(\mu)$.

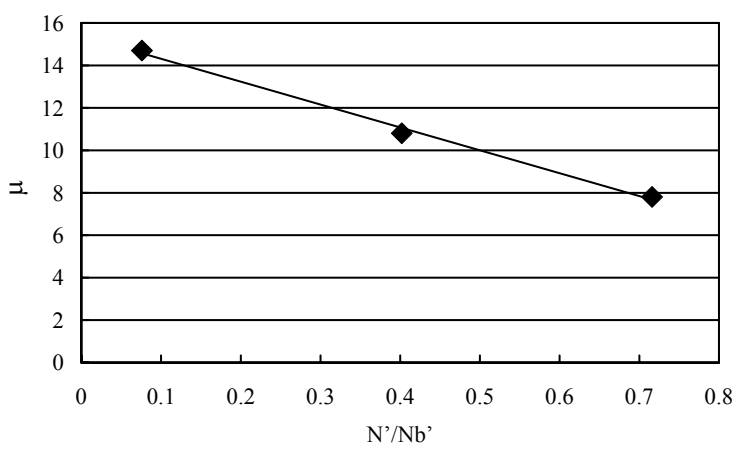

Fig.22 Relationship between N'/N'b and ductility $(\mu)$.

where the ratio is between approx. 1.0 and approx. 1.4. Judging from these experimental results, the ductility ratio becomes higher than 10 and then 15 when the shear-to-flexural capacity ratio exceeds 1.0 and 1.4, respectively.

Figure 22 shows the relations between axial compressive force ratio $\left(\mathrm{N}^{\prime} / \mathrm{N}_{\mathrm{b}}\right.$,, $\mathrm{N}^{\prime}$ : axial force, $\mathrm{N}_{\mathrm{b}}$ ': equilibrium axial force) and ductility ratio for specimens IV-1, VII-1, and VII-2, which had different axial compressive stresses. This figure tells us that the ductility ratio of $\mathrm{RC}$ columns retrofitted with our method gradually decrease as the axial compressive stress increases. This tendency matches that of normal reinforced con- crete columns.

\subsection{Design method}

From the experimental results, the retrofitting design methods are designed as follows. These design methods can be applied to columns of rigid frame reinforced concrete railway structures on condition that compressive stress caused by permanent loads is smaller than 3 $\mathrm{N} / \mathrm{mm}^{2}$.

In the top and bottom regions of the column with the length of $2 D$ ( $D$ : height of column section), retrofitting bars must be arranged to satisfy the inequality as follows.

$$
\gamma_{\mathrm{i}} \cdot V_{\mathrm{yd}} / V_{\mathrm{mu}}>1.5
$$

In the other region, bars must be arranged to satisfy the inequality as follows.

$$
\gamma_{\mathrm{i}} \cdot V_{\mathrm{mu}} / V_{\mathrm{yd}}<1.0
$$

where, $\gamma_{\mathrm{i}}$ : structural factor $=1.0, V_{\mathrm{yd}}$ : shear strength and $V_{\mathrm{mu}}$ : shear at moment capacity.

The shear capacity $V_{\text {yd }}$ in Eqns. (1) and (2) is assumed as the sum of $V_{\mathrm{c}}$ : shear strength held by concrete and $V_{\text {rs }}$ : shear strength held by retrofitting bars.

The value of $V_{\mathrm{c}}$ : strength without shear reinforcement is estimated by the Eq. (3).

$$
V_{\mathrm{c}}=\beta_{\mathrm{d}} \beta_{\mathrm{p}} \cdot \beta_{\mathrm{n}} \cdot \mathrm{f}_{\mathrm{vcd}} \cdot \mathrm{b}_{\mathrm{w}} \mathrm{d} / \gamma_{\mathrm{b}}
$$

where, $f_{\mathrm{vcd}}=0.2 f_{\mathrm{ck}}^{1 / 3}, f^{\prime} \mathrm{ck}$ : compressive strength of concrete, $\beta_{\mathrm{d}}$ : modifier considering scale effect $=(1000 / \mathrm{d})^{1 / 4}$ $=<1.5, \beta_{\mathrm{p}}$ : modifier considering amount of transverse reinforcement $=\left(100 p_{\mathrm{c}}\right)^{1 / 3}=<1.5, \beta_{\mathrm{n}}$ : modifier considering design axial stress $=1+M_{0} / M_{\mathrm{d}}=<2\left(N_{\mathrm{d}}{ }_{\mathrm{d}}=>0\right)$ or $1+2 M_{0} / M_{\mathrm{d}}=>0\left(N^{\prime}{ }_{\mathrm{d}}<0\right), \mathrm{b}_{\mathrm{w}}$ : width of section, d: effective depth, $\mathrm{p}_{\mathrm{c}}=A_{\mathrm{s}} /\left(b_{\mathrm{w}} \cdot d\right), A_{\mathrm{s}}$ : sectional area of tensile reinforcements, $M_{\mathrm{d}}$ : design moment, $M_{0}$ : decompression moment, $N^{\prime}{ }_{\mathrm{d}}$ : axial force, and $\gamma_{\mathrm{b}}$ : member safety factor.

The value of $V_{\mathrm{rs}}$ : shear strength held by retrofitting bars is estimated by Eq. (4).

$$
V_{\mathrm{rs}}=A_{\mathrm{w}} \cdot f_{\mathrm{wyd}} / \mathrm{s}_{\mathrm{s}} \mathrm{z} / \gamma_{\mathrm{b}}
$$

where, $A_{\mathrm{w}}$ : sectional area of retrofitting bar in section " $\mathrm{s}_{\mathrm{s}}$ ", $f_{\mathrm{wyd}}$ : yield strength of retrofitting bar, $\mathrm{s}_{\mathrm{s}}$ : spacing of retrofitting bars, $\mathrm{z}=\mathrm{d} / 1.15$, $\mathrm{d}$ : effective depth, and $\gamma_{\mathrm{b}}$ : member safety factor.

The shear at moment capacity is estimated as the horizontal force when the sectional force at the bottom of the column reaches the ultimate flexural strength. Thus, the value of $V_{\mathrm{mu}}$ is estimated by Eq. (5).

$$
V_{\mathrm{mu}}=M_{\mathrm{u}} / l_{\mathrm{a}}
$$

where, $M_{\mathrm{u}}$ : flexural strength, and $\mathrm{l}_{\mathrm{a}}$ : shear span.

\section{Single-face method}

Figure 23 is the schematic drawing of the single-face method. The characteristics of this method are described 


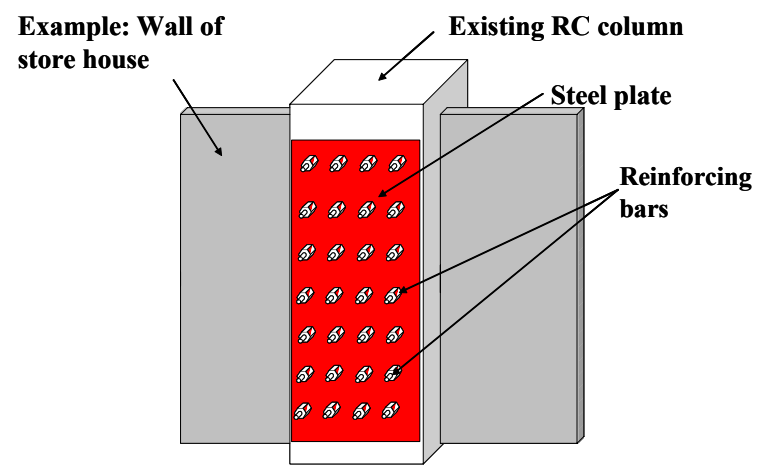

Fig. 23 Schematic drawing of single-face method.

above.

\subsection{Outline of the examinations}

Figure 24 shows the cross sections. Table 4 shows the specified properties of the specimens. Specimen No. 1 has normal hoop reinforcements inside the section. This specimen serves as a standard one to be compared with other specimens. Specimens No. 2 to No. 9 have single-face retrofitting reinforcements and internal hoop reinforcements in the section. All the specimens have the same sectional size and the same shear span to depth ratio. The direction of loading is shown in Fig. 24. The main testing parameter is the retrofitting reinforcement ratio.

The loading method is the same as that of the RB method.

\subsection{Experimental results and discussion}

(1) Comparison of RC specimen and seismic retrofitted specimens

Cyclic load-displacement relations of specimens No. 1, No. 2 and No. 7 are shown in Fig. 25, Fig. 26 and Fig. 27, respectively.

As shown in Fig. 25, specimen No. 1 with normal reinforcements lost load resistance sharply just after main reinforcements yielded. The ductility ratio of specimen No. 2 retrofitted by one face retrofitting reinforcements is larger than that of No. 1. On the other hand, specimen No. 7 retrofitted in a different direction showed the same ductility. Other specimens did not show rapid descent of load as seen in the case of specimen No. 1.

\section{(2) Effect of Shear-to-Moment capacity ratio to} ductility ratio

Effect of reinforcing bars on seismic performance

Table 5 shows the material properties and the experimental values of ductility ratio.

Figure 28 shows the envelopes of the cyclic load-displacement relations of specimens ranging from No. 2 to No. 5, which have different shear-to-moment capacity ratio. If the shear-to-moment capacity ratio is

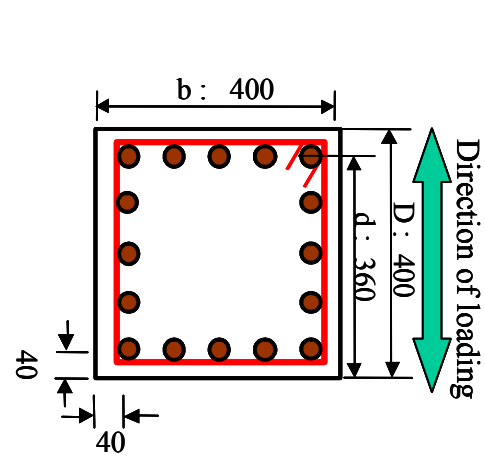

(a) No. 1

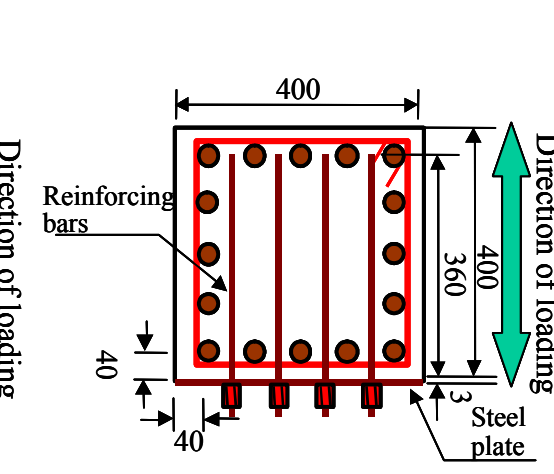

(b) No. 2, 3, 4, 5

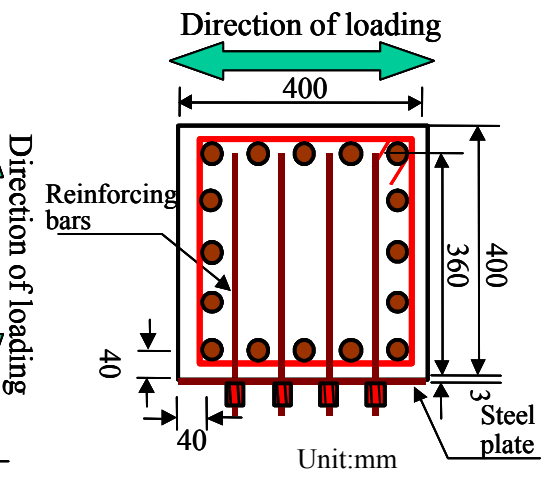

(c) No. 6, 7, 8, 9

Fig. 24 Cross sections of specimens.

Table 4 Properties of specimens.

\begin{tabular}{|c|c|c|c|c|c|c|c|}
\hline \multirow{3}{*}{$\begin{array}{l}\text { Specimen } \\
\text { number }\end{array}$} & \multirow{3}{*}{$\begin{array}{l}\text { Section } \\
\text { size } \\
b \times D(\mathrm{~mm})\end{array}$} & \multirow{3}{*}{$\begin{array}{l}\text { Shear } \\
\text { span } \\
\text { la(mm) }\end{array}$} & \multirow{3}{*}{$\begin{array}{l}\text { Effective } \\
\text { depth } \\
d(\mathrm{~mm})\end{array}$} & \multirow{3}{*}{$\begin{array}{l}\text { Arrangements of } \\
\text { axial reinforcements } \\
\text { (SD345) }\end{array}$} & \multirow{3}{*}{$\begin{array}{l}\text { Arrangements of } \\
\text { hoop reinforcements } \\
\text { (SD345) }\end{array}$} & \multicolumn{2}{|c|}{ Retrofitting reinforcements } \\
\hline & & & & & & Steel plate & \multirow{2}{*}{\begin{tabular}{|l} 
Reinforcing bars \\
(SD345)
\end{tabular}} \\
\hline & & & & & & $(\mathrm{SS} 400)(\mathrm{mm})$ & \\
\hline No.2 & \multirow{7}{*}{$400 \times 400$} & \multirow{7}{*}{1150} & \multirow{7}{*}{360} & \multirow{7}{*}{$\mathrm{D} 19 \times 16$} & \multirow{7}{*}{ D6@200 } & 3 & D13@150 \\
\hline No.3 & & & & & & 3 & D13@100 \\
\hline No.4 & & & & & & 3 & D13@250 \\
\hline No.6 & & & & & & 3 & D13@150 \\
\hline No.7 & & & & & & 4.5 & D13@150 \\
\hline No.8 & & & & & & 9 & D13@150 \\
\hline No.9 & & & & & & 14 & D13@150 \\
\hline
\end{tabular}


equal to or larger than 1.5 , the load-displacement relationships will be almost same.

Figure 29 shows the relationships between shear-to-flexural capacity ratio and ductility ratio. The ductility ratios of these specimens with one face retrofitting reinforcements are about 8 or more if the shear-to-flexural capacity ratio is equal to or larger than 1.3. However, even where the shear-to-flexural capacity ratio exceeds 1.5 , the ductility ratio does not increase.

\section{Effect of steel plate on seismic performance}

Figure 30 shows the envelopes of the cyclic load-displacement relations of specimens No. 6 to No. 9 . As shown in the figure, ductility increases gently with the increase in the shear-to-flexural capacity ratio.

Figure 31 shows the relationships between the shear-to-flexural capacity ratio and ductility ratio of different specimens. The ductility ratios of these specimens are 6 or more if the shear-to-flexural capacity ratio is equal to or larger than 1.4. The ductility ratio also shows the tendency to increase fairly steadily as the shear-to-flexural capacity ratio increases.

\subsection{Design method}

From the experimental results, the retrofitting design methods were designed as follows. These design methods can be applied to columns of rigid frame reinforced concrete railway structures on condition that compressive stress caused by permanent loads is smaller than 3 $\mathrm{N} / \mathrm{mm}^{2}$.

\section{(1) Design of retrofitting bars}

In the top and bottom regions of the column with the length of $2 \mathrm{D}$, retrofitting bars must be arranged to satisfy the following inequality.

$$
\gamma_{\mathrm{i}} \cdot V_{\mathrm{yd}} / V_{\mathrm{mu}}>2.0
$$

In the other region, bars must be arranged to satisfy the following inequality.

$$
\gamma_{\mathrm{i}} \cdot V_{\mathrm{mu}} / V_{\mathrm{yd}}<1.0
$$

where, $\gamma_{\mathrm{i}}$ : structural factor $=1.0, V_{\mathrm{yd}}$ : shear strength and $V_{\mathrm{mu}}$ : shear at moment capacity.

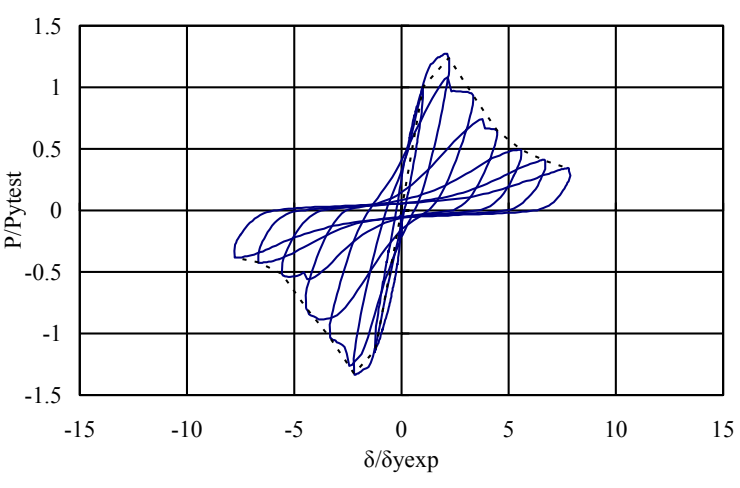

Fig. 25 Cyclic load-displacement relation (No. 1).

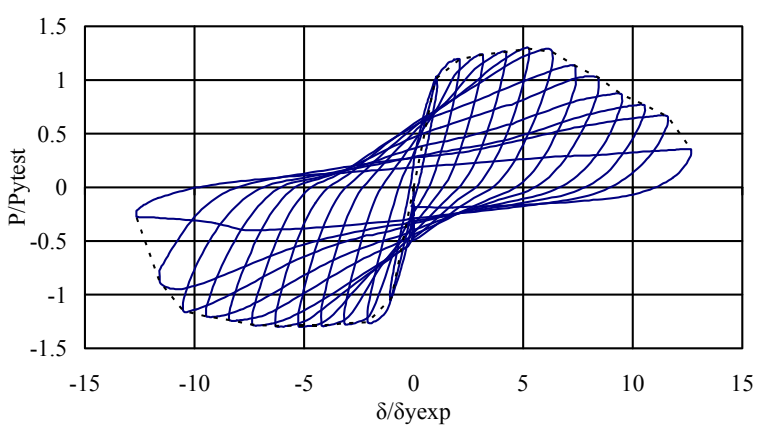

Fig. 26 Cyclic load-displacement relation (No. 2).

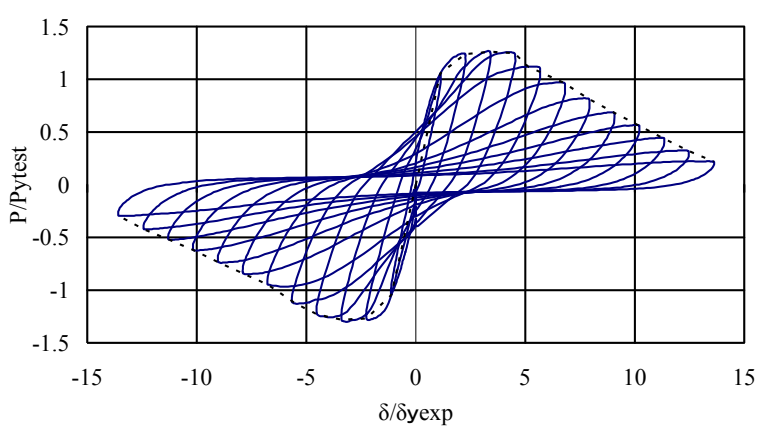

Fig. 27 Cyclic load-displacement relation (No. 7).

\begin{tabular}{|c|c|c|c|c|c|c|c|c|c|}
\hline \multirow{2}{*}{$\begin{array}{c}\text { Specimen } \\
\text { number }\end{array}$} & \multicolumn{2}{|c|}{ Material strength } & \multicolumn{3}{|c|}{ Calculated value } & \multicolumn{3}{|c|}{ Experimental Value } & \multirow[b]{2}{*}{ 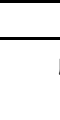 } \\
\hline & $\begin{array}{c}f^{\prime} \mathrm{c} \\
\left(\mathrm{N} / \mathrm{mm}^{2}\right)\end{array}$ & $\begin{array}{c}f \text { syl } \\
\left(\mathrm{N} / \mathrm{mm}^{2}\right)\end{array}$ & $\begin{array}{c}f_{\text {sy2 } 2} \\
\left(\mathrm{~N} / \mathrm{mm}^{2}\right)\end{array}$ & $\begin{array}{l}V y d \\
(\mathrm{kN})\end{array}$ & $\begin{array}{l}V \mathrm{mu} \\
(\mathrm{kN})\end{array}$ & $V \mathrm{yd} / V \mathrm{mu}$ & 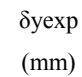 & $\begin{array}{l}\text { Suexp } \\
\text { (mm) }\end{array}$ & \\
\hline No. 1 & 26.7 & 369 & 355 & 203 & 251 & 0.8 & 6.3 & 14.5 & 2.3 \\
\hline No. 2 & 28.7 & 369 & 355 & 543 & 253 & 2.1 & 5.9 & 57.3 & 9.8 \\
\hline No. 3 & 29.7 & 388 & 355 & 716 & 265 & 2.7 & 5.6 & 51.6 & 9.3 \\
\hline No. 4 & 31.2 & 388 & 355 & 412 & 267 & 1.5 & 5.7 & 52.2 & 9.2 \\
\hline No. 5 & 29.9 & 388 & 355 & 332 & 265 & 1.3 & 5.8 & 45.1 & 7.8 \\
\hline No. 6 & 21.1 & 388 & 355 & 351 & 253 & 1.4 & 6.2 & 38.1 & 6.2 \\
\hline No. 7 & 30.4 & 388 & 355 & 452 & 266 & 1.7 & 5.8 & 38.6 & 6.7 \\
\hline No. 8 & 32.1 & 388 & 355 & 779 & 268 & 2.9 & 5.5 & 44.2 & 8.0 \\
\hline No. 9 & 18.0 & 406 & 381 & 1149 & 258 & 4.5 & 4.0 & 37.2 & 9.4 \\
\hline
\end{tabular}

Table 5 Material properties and experimental values.

Note: f'c: concrete strength of the column, fsyl: yield strength of axial reinforcement, fsy2: yield strength of hoop reinforcement, $\delta$ yexp: yield displacement, $\delta$ uexp: ultimate displacement, $\mu$ : ductility ratio 


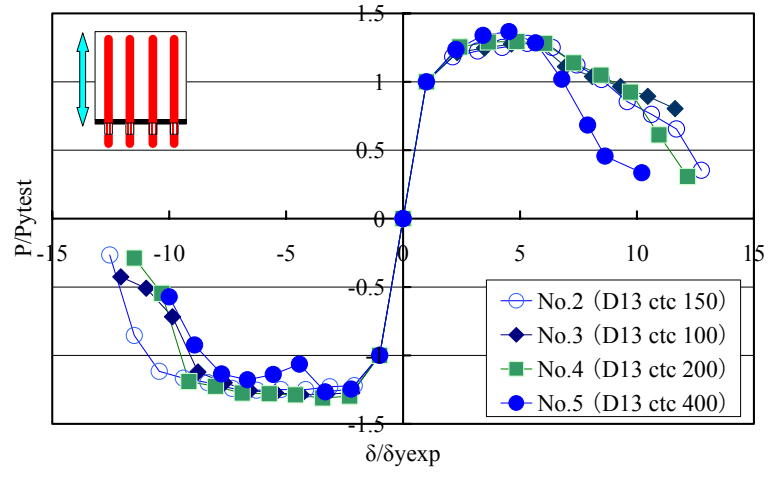

Fig. 28 Envelope of cyclic load-sidplacement relation (No. 2, 3, 4, 5).

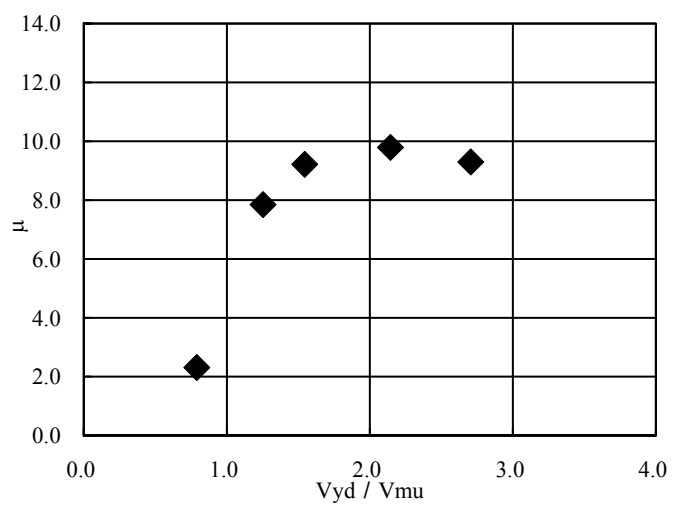

Fig.29 Relationship between $V y d / V m u$ and ductility $(\mu)$.

The shear capacity $V_{\text {yd }}$ in Eqns. (6) and (7) is assumed as the sum of $V_{\mathrm{c}}$ : shear strength held by concrete, and $V_{\mathrm{rs}}$ : shear strength held by retrofitting bars.

The value of $V_{\mathrm{c}}$ : strength without shear reinforcement is estimated by the Eq. (3).

The value of $V_{\mathrm{rs}}$ : shear strength held by retrofitting bars is estimated by the Eq. (8).

$$
V_{\mathrm{rs}}=A_{\mathrm{w}} \cdot f_{\mathrm{wyd}} / s_{\mathrm{s}} z / \gamma_{\mathrm{b}}
$$

where, $A_{\mathrm{w}}$ : sectional area of retrofitting bar in section " $s_{\mathrm{s}}$ ", $f_{\mathrm{wyd}}$ : yield strength of retrofitting bar, $\mathrm{s}_{\mathrm{s}}$ : spacing of retrofitting bars, $z=d / 1.15$, d: effective depth, and $\gamma_{\mathrm{b}}$ : member safety factor.

The shear at moment capacity is estimated as the horizontal force when the sectional force at the bottom of the column reaches the ultimate flexural strength. Thus, the value of $V_{\mathrm{mu}}$ is estimated by Eq. (9).

$$
V_{\mathrm{mu}}=M_{\mathrm{u}} / l_{\mathrm{a}}
$$

where, $M_{\mathrm{u}}$ : flexural strength, and $\mathrm{l}_{\mathrm{a}}$ : shear span.

\section{(2) Design of retrofitting plate}

In the top and bottom regions of the column with the length of $2 \mathrm{D}$, retrofitting bars must be arranged to satisfy the following inequality.

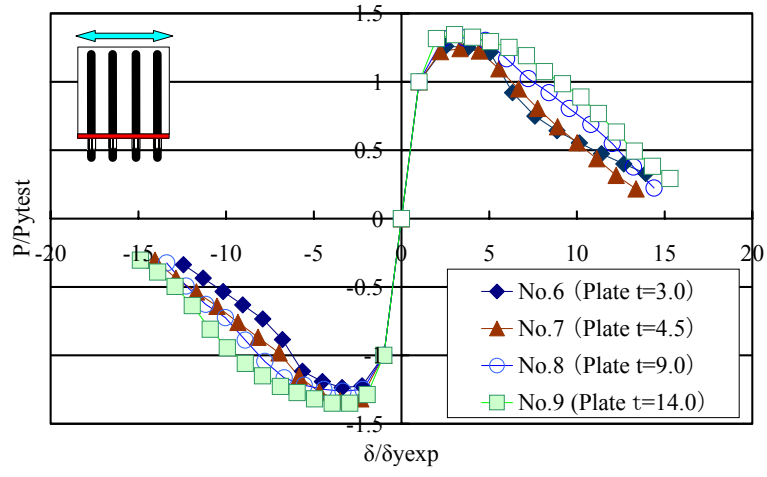

Fig. 30 Envelope of cyclic load-displacement relation (No. 6, 7, 8, 9).

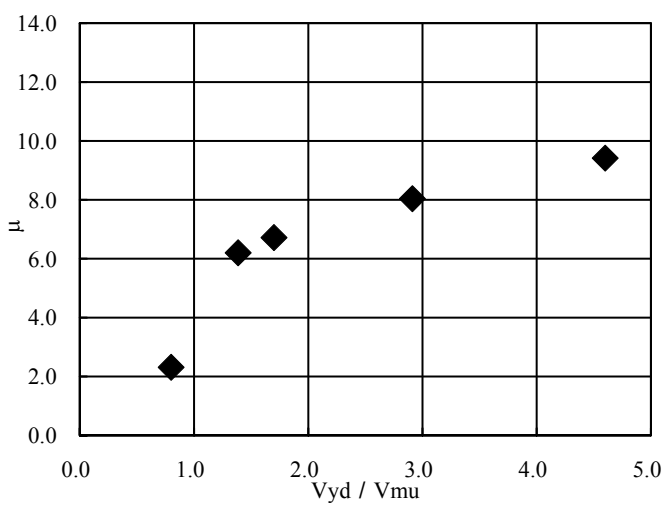

Fig.31 Relationship between $V y d / V m u$ and ductility $(\mu)$.

$$
\gamma_{\mathrm{i}} \cdot V_{\mathrm{yd}} / V_{\mathrm{mu}}>1.4
$$

In the other region, bars must be arranged to satisfy the following inequality.

$$
\gamma_{\mathrm{i}} \cdot V_{\mathrm{mu}} / V_{\mathrm{yd}}<1.0
$$

where, $\gamma_{\mathrm{i}}$ : structural factor $=1.0, V_{\mathrm{yd}}$ : shear strength and $V_{\text {mu }}$ : shear at moment capacity.

The shear capacity $V_{\mathrm{yd}}$ in Eqns. (10) and (11) is assumed as the sum of $V_{\mathrm{c}}$ : shear strength held by concrete, and $V_{\mathrm{rp}}$ : shear strength held by retrofitting plates.

The value of $V_{\mathrm{c}}$ : strength without shear reinforcement is estimated by the Eq. (3).

The value of $V_{\mathrm{rp}}$ : shear strength held by retrofitting plated is estimated by the Eqns. (12), (13), (14), and (15).

$$
\begin{aligned}
& V \mathrm{rp}=f(s) . V s y \\
& V \mathrm{sy}=f v y . t w . z w / \gamma b \\
& f(\mathrm{~s})=2.7+0.16 k-0.68(a / d) \\
& 0.6 \leqq f(s) \leqq 2.5 \\
& 1.0 \leqq a / d \leqq 3.5 \\
& 2.0 \leqq k \leqq 7.0
\end{aligned}
$$




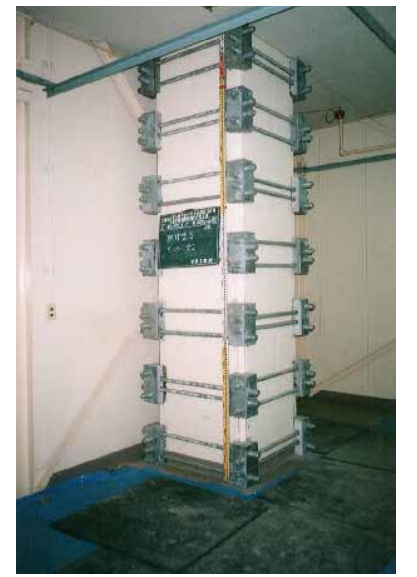

Fig. 32 RB method completed.

$$
f_{v y}=\left(f_{s y k} / 3\right)^{\frac{1}{2}} / \gamma_{s}
$$

where, $t_{\mathrm{w}}$ : thickness of retrofitting plate, $z_{\mathrm{w}}$ : width of retrofitting plate, $\gamma_{\mathrm{b}}$ : member safety factor, $k$ : modifier considering plate thickness $=t_{\mathrm{w}} z_{\mathrm{w}} /\left(b_{\mathrm{w}} \cdot d\right), b_{\mathrm{w}}$ : width of section, $d$ : effective depth of section, a: shear span, $\gamma_{\mathrm{s}}$ : material safety factor.

The shear at moment capacity is estimated as the horizontal force when the sectional force at the bottom of the column reaches the ultimate flexural strength. Thus, the value of $V_{\mathrm{mu}}$ is estimated by Eq. (16)

$$
V_{\mathrm{mu}}=M_{\mathrm{u}} / l_{\mathrm{a}}
$$

where, $M_{\mathrm{u}}$ : flexural strength, and $l_{\mathrm{a}}$ : shear span.

\section{Conclusion}

This paper has outlined the seismic retrofitting of rail-

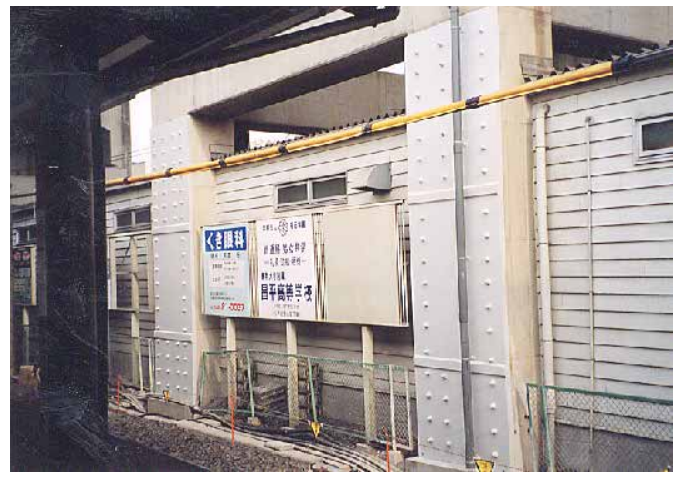

Fig. 33 Single-face method completed.

way concrete structures and reported on the experimental results of two new seismic retrofitting methods. In the first method, which is called the RB method, retrofitting bars are arranged so as to keep the value of $\gamma_{\mathrm{i}} \cdot V_{\mathrm{yd}} / V_{\mathrm{mu}}$ above 1.5. In the second method, which is called the single-face method, retrofitting bars are arranged so as to keep the value of $\gamma_{\mathrm{i}} \cdot V_{\mathrm{yd}} / V_{\mathrm{mu}}$ above 2.0. Moreover, retrofitting plates are arranged so as to keep the value of $\gamma_{\mathrm{i}} \cdot V_{\mathrm{yd}} / V_{\mathrm{mu}}$ above 1.4.

These methods are actually used for the seismic retrofitting of railway structures as shown in Fig. 32 and Fig. 33.

\section{References}

Railway Technical Research Institute, (1992). "Standard specification for design of concrete structure for railways." (in Japanese).

Railway Technical Research Institute, (1992). "Standard specification for seismic design of structures for railways." (in Japanese). 